\title{
Effect of combinations of wood and counterface materials on three-body abrasive wear
}

Received: May 27, 2002 / Accepted: December 2, 2002

\begin{abstract}
The abrasion characteristics of various combinations of wood and counterface materials in three-body abrasive wear were investigated. Various wood samples were examined in combination with wood, plastic, and metal counterface materials. The wear coefficient in the wood samples was calculated as the wear volume of the friction surface divided by the sliding distance and the applied load. The results showed that the wear coefficient was smaller in cases where the wood samples had greater yield stress. The wear coefficient increased as the yield stress of the various counterface materials increased, reaching a maximum value and then decreased as the yield stress increased. This result indicated that a peak value existed for the wear coefficient in combination with the counterface material.
\end{abstract}

Key words Three-body abrasive wear - Wear coefficient . Counterface materials $\cdot$ Loose abrasive grain $\cdot$ Yield stress

\section{Introduction}

Materials undergo abrasive wear when abrasive grains scratch the surface. Abrasive wear can occur as two-body abrasive wear (in which asperities on the abrasive material abrade the softer material) and three-body abrasive wear (in which loose abrasive particles remove the softer material). ${ }^{1,2}$ Two-body abrasive wear includes sanding and polishing for wood products using abrasive paper or abrasive cloth. With two-body abrasive wear, wood becomes more difficult to abrade as the yield stress and density of the wood increases; the microstructure of the wood surface also

T. Ohtani $(\bowtie) \cdot$ K. Kamasaki $\cdot$ C. Tanaka

Faculty of Science and Engineering, Shimane University, 1060

Nishikawatsu-cho, Matsue 690-8504, Japan

Tel. +81-852-32-6207; Fax +81-852-32-6123

e-mail: t-ohtani@riko.shimane-u.ac.jp

Part of this report was presented at the 51st Annual Meeting of the Japan Wood Research Society, Tokyo, April 2001 affects abrasive wear. ${ }^{3,4}$ Three-body abrasive wear of wood flooring occurs when pedestrians bring foreign objects into forced contact with the wood. It has been reported that three-body abrasive wear of wood is governed by the scratching action of loose abrasive grains in addition to the conditions defined in two-body abrasive wear. ${ }^{5}$ However, it is difficult to completely understand the minute scratching action of loose abrasive grains in random motion.

When we think of three-body abrasion between the wood and counterface material, the surface properties of the counterface material affect the fixation of abrasive particles and hence the degree of abrasive wear on the wood. Therefore, counterface material is one of the most important factors to affect the scratching action of three-body abrasion. The effect on the counterface material is reported to be three-body abrasion between metal marks in combination with the counterface material. ${ }^{6}$ It has been shown that this tendency relates closely to the ability of the abrasive grains to embed in the counterface material, and that the degree of embedding ability is optimum when there is a large amount of abrasive wear. Therefore, the addition of counterface material may affect the rubbing with the wood material. In this study, we examine the effect of combinations of various types of wood and counterface materials on three-body abrasive wear.

\section{Materials and methods}

Materials

Various wood samples were used as specimens for rubbing; and various types of wood, plastics, and metal were used as counterface materials. Tables 1 and 2 show the properties of the wood specimens and the counterface materials, respectively. The hardwood specimens used in this study were kiri (Paulownia tomentosa Steud.), sawagurumi (Pterocarya rhoifolia Sieb. et Zucc.), and itayakaede (Acer mono Maxim.). The softwood specimens were sawara (Chamaecyparis pisifera Endl.), yezomatsu (Picea jezoensis 
Table 1. Properties of the wood specimens used for the experiment

\begin{tabular}{|c|c|c|c|c|c|}
\hline Specimen & $\begin{array}{l}\text { Softwood or } \\
\text { hardwood }\end{array}$ & $\begin{array}{l}\text { Density } \\
\left(\mathrm{g} / \mathrm{cm}^{3}\right)\end{array}$ & $\begin{array}{l}\text { Moisture } \\
\text { content (\%) }\end{array}$ & $\begin{array}{l}\text { Average width of } \\
\text { annual rings }(\mathrm{mm})\end{array}$ & $\begin{array}{l}\text { Yield stress } \\
\sigma_{\mathrm{y}}(\mathrm{MPa})\end{array}$ \\
\hline Kiri (Paulownia tomentosa Steud.) & $\mathrm{H}$ & 0.29 & 11.5 & 23.0 & 21 \\
\hline Sawara (Chamaecyparis pisifera Endl.) & $\mathrm{S}$ & 0.34 & 11.5 & 1.8 & 29 \\
\hline Yezomatsu (Picea jezoensis Carr.) & $\mathrm{S}$ & 0.36 & 12.5 & 1.8 & 37 \\
\hline Sawagurumi (Pterocarya rhoifolia Sieb. et Zucc.) & $\mathrm{H}$ & 0.39 & 8.4 & 4.2 & 42 \\
\hline Momi (Abies firma Sieb. et Zucc.) & $\mathrm{S}$ & 0.45 & 10.1 & 1.9 & 47 \\
\hline Kuromatsu (Pinus thunber gii Parl) & $\mathrm{S}$ & 0.55 & 12.2 & 3.9 & 55 \\
\hline Itayakaede (Acer mono Maxim.) & $\mathrm{H}$ & 0.66 & 9.4 & 3.6 & 61 \\
\hline
\end{tabular}

$\mathrm{H}$, hardwood; S, softwood

Table 2. Properties of the counterface materials used for the experiment

\begin{tabular}{llll}
\hline Counterface material & $\begin{array}{l}\text { Density } \\
\left(\mathrm{g} / \mathrm{cm}^{3}\right)\end{array}$ & $\begin{array}{l}\text { Yield stress } \\
\sigma_{\mathrm{y}}(\mathrm{MPa})\end{array}$ & $\begin{array}{l}\text { Arithmetical mean deviation } \\
R_{\mathrm{a}}(\mu \mathrm{m})\end{array}$ \\
\hline Wood & & & \\
$\quad$ Sawara & 0.34 & 29 & $1.23 \pm 0.14$ \\
$\quad$ Kuromatsu & 0.55 & 55 & $2.91 \pm 0.93$ \\
Plastic & & & \\
$\quad$ Polypropylene (PP) & 0.90 & 21 & $0.24 \pm 0.02$ \\
$\quad$ Polyethylene (PE) & 0.98 & 17 & $0.20 \pm 0.03$ \\
$\quad$ Acrylic resin (PMMA) & 1.21 & 66 & $0.21 \pm 0.01$ \\
Metal & & & \\
$\quad$ Pure aluminum (A1050) & 2.64 & 85 & $0.16 \pm 0.02$ \\
$\quad$ Carbon steel (SS400) & 7.04 & 440 & $0.18 \pm 0.02$ \\
$\quad$ Cast iron (FC250) & 7.75 & 216 & $0.14 \pm 0.02$ \\
$\quad$ Pure copper (C1100) & 8.77 & 147 & $0.15 \pm 0.01$ \\
\hline
\end{tabular}

Carr.), momi (Abies firma Sieb. et Zucc.), and kuromatsu (Pinus thunber gii Parl). The densities of these materials ranged from 0.29 to $0.66 \mathrm{~g} / \mathrm{cm}^{3}$, the moisture contents from $8.4 \%$ to $12.5 \%$, and the average width of annual rings from 1.8 to $23.0 \mathrm{~mm}$. The yield stress obtained from the results of a compression test ranged from 21 to $61 \mathrm{MPa}$. The contact surface of each wood specimen was cut to dimensions of $3 \mathrm{~mm}$ (tangential direction, $\mathrm{T}) \times 4 \mathrm{~mm}$ (radial direction, $\mathrm{R}$ ) and was finished by sanding with no. 600 abrasive paper.

The various counterface materials used, shown in Table 2, were softwood (sawara and kuromatsu), plastics [polypropylene (PP), polyethylene (PE), acrylic resin [PMMA], and metals [pure aluminum (A1050), carbon steel (SS400), cast iron (FC250), pure copper (C1100)]. The yield stress ranged from 17 to $440 \mathrm{MPa}$. The surface roughness of the counterface materials after sanding with no. 600 abrasive paper was evaluated in terms of the arithmetical mean deviation $\left(R_{\mathrm{a}}\right)$ of the surface profile. The $R_{\mathrm{a}}$ value for wood counterface materials was larger than the $R_{\mathrm{a}}$ values for plastic $(\sim 0.2 \mu \mathrm{m})$ or metal $(\sim 0.15 \mu \mathrm{m})$ because of the honeycomb structure of the axial section of the wood.

\section{Abrasive wear test}

Three-body abrasive wear test in this study was not only conducted by the simple method of rubbing repeatedly, it also was adapted to attempt compatibility with the twobody abrasive wear test, as shown in a previous report. ${ }^{7}$ Figure 1 shows the apparatus used to perform the threebody abrasive wear test. In the test procedure, the

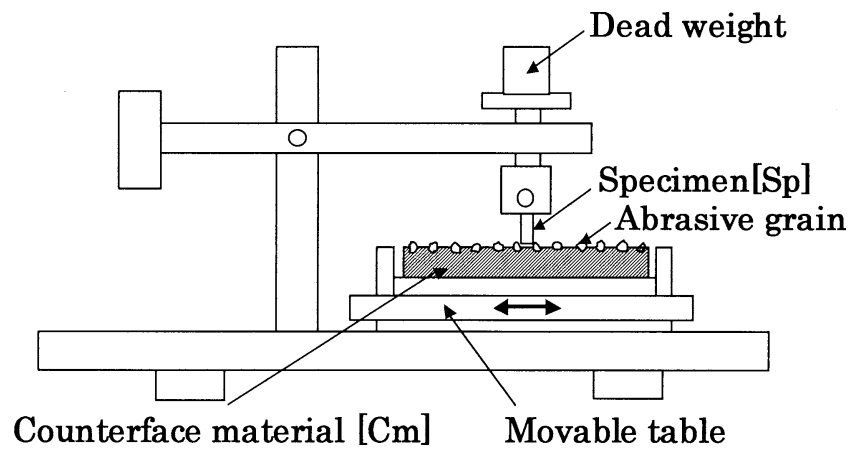

Fig. 1. Three-body abrasive wear test

counterface material was attached to the movable table, abrasive grains were applied to the counterface material, and the wood specimen was brought into contact with the counterface. The counterface material on the movable table was moved back and forth along a $100 \mathrm{~mm}$ line at $20 \mathrm{~mm} / \mathrm{s}$, causing abrasive wear. The abrasive grain material was no. $100 \mathrm{Al}_{2} \mathrm{O}_{3}$ (mean abrasive grain size $150 \mu \mathrm{m}$ ), and $1.5 \mathrm{~g}$ was scattered during each abrasive wear test. After the abrasive grain was smoothly scattered on the counterface material, the wood specimen was rubbed at an applied pressure of $0.08 \mathrm{MPa}$. To confirm the amount of loose abrasive grains during abrasion, the number of abrasive grains rubbed with the wood specimen was examined on sawara wood counterface material, as shown in Fig. 2. Consequently, the grains rubbed into kiri, momi, and itayakaede wood specimens numbered $18.8 \pm 0.51 \mathrm{~mm}^{-2}$ in cases where the wear 


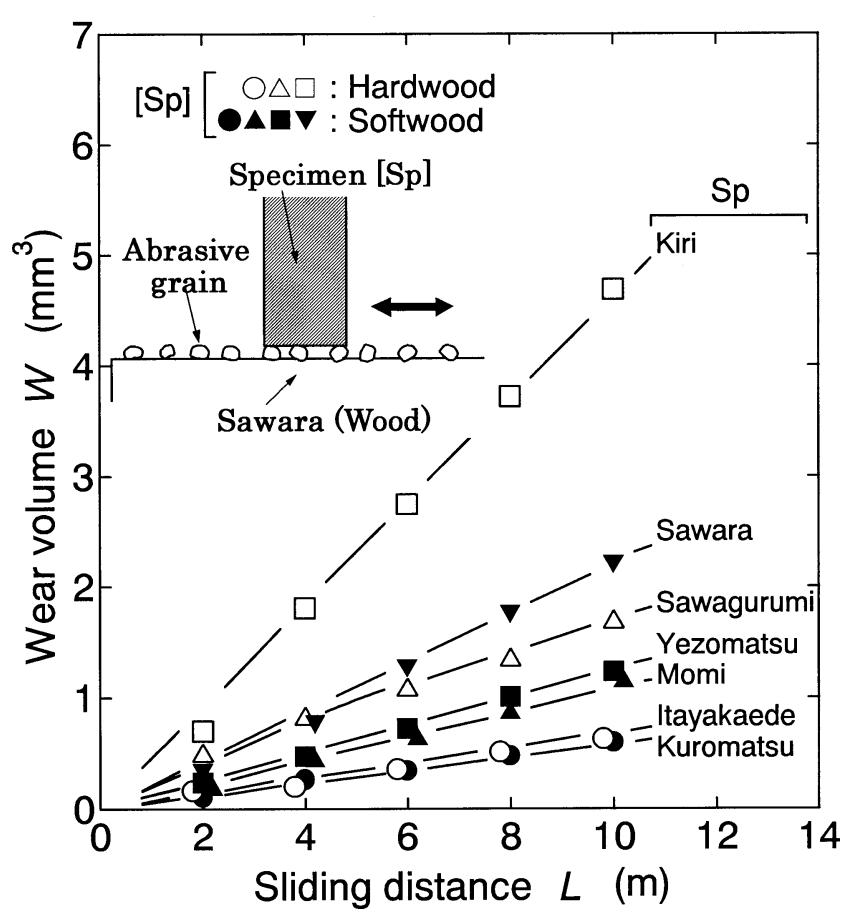

Fig. 2. Relation between the wear volume $(W)$ of the wood specimen and sliding distance $(L)$ during the abrasive wear test of sawara wood counterface material

volume $(W)$ increased linearly as the sliding distance $(L)$ increased. The numbers in combination with $\mathrm{PE}$ and $\mathrm{Al}$ counterface materials were $18.5 \pm 0.79$ and $18.6 \pm$ $0.73 \mathrm{~mm}^{-2}$, respectively. Because the number of abrasive grains was constantly in contact with some combination materials, the wear coefficient was estimated from the linear range of the $W-L$ curves.

\section{Results and discussion}

Three-body abrasive wear property of wood

Figure 2 shows the relation between the wear volume $(W)$ of the wood specimen and the sliding distance $(L)$ on sawara wood counterface material. $W$ increases with $L$ in all wood specimens. This tendency was recognized for all of the counterface materials. The wear coefficient $\left(W_{\mathrm{s}}\right)$ was then calculated from the linear range of the $W-L$ curves as the wear volume (cubic millimeters) divided by the sliding distance (millimeters) and the applied load (newtons). Figure 3 shows the relation between $W_{\mathrm{s}}$ and the yield stress $\left(\sigma_{\mathrm{y}[\mathrm{Sp}]}\right)$ for wood specimens rubbed against wood counterface materials. $W_{\mathrm{s}}$ is smaller when the wood specimen has greater yield stress. Moreover, $W_{\mathrm{s}}$ for the hardwood specimens tends to be larger than that for the softwood specimens. Figures 4 and 5 show the relation between $W_{\mathrm{s}}$ and $\sigma_{\mathrm{y}[\mathrm{Spl}}$ for plastic and metal counterface materials. In both figures, $W_{\mathrm{s}}$ is smaller when the wood specimen has greater yield stress, similar to the tendency seen in Fig. 3 . The $W_{\mathrm{s}}$ of the hardwood specimens also tends to be larger

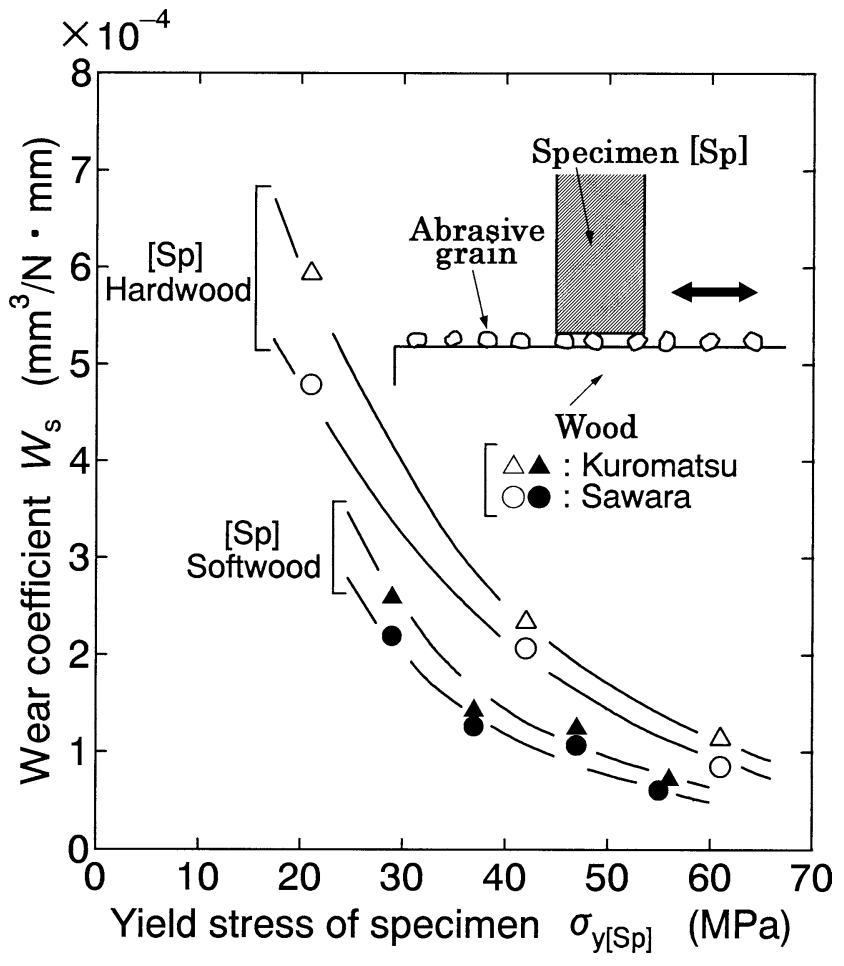

Fig. 3. Relation between the wear coefficients $\left(W_{\mathrm{s}}\right)$ and yield stresses $\left(\sigma_{\mathrm{y}[\mathrm{Sp}]}\right)$ of wood specimens combined with wood counterface materials

than that of the softwood specimens for the plastic and metal counterface materials. These results reveal that wood specimens with higher yield stress are more difficult to abrade, with all combinations of the wood, plastic, and metal counterface materials.

Effect of combinations of counterface material during three-body abrasive wear

Figure 6 shows the wear coefficient for each wood specimen relative to the yield stress of the counterface material $\left(\sigma_{\mathrm{y}[\mathrm{Cm}]}\right)$. The figure includes all the data from Figs. 3, 4, and 5. For all wood specimens, $W_{\mathrm{s}}$ increases to a maximum and then decreases gradually with increasing $\sigma_{\mathrm{y}[\mathrm{Cm}]}$. This result indicates that a peak value exists for $W_{\mathrm{s}}$ in combination with the counterface material.

Figure 7 shows the surface of the yezomatsu specimen before and after the abrasive wear test. Figure 7a shows the surface prior to the abrasive wear test, and Fig. 7b-d shows the surfaces after abrasion for a total distance of $1.6 \mathrm{~m}$ on PE, A1050, and SS400. Figure 8 shows similar results for the sawagurumi specimen. More than twice the number of loose abrasive grains are observed for A1050 and SS400 than for PE when the peak $W_{\mathrm{s}}$ is exceeded. The vessel structure is observable on the surface of the sawagurumi specimen, and loose abrasive grains adhering to the cavities of the specimen can be observed on part of the specimen structure after the test.

The abrasive grains adhering to the surface were removed using compressed air, and the arithmetical mean 


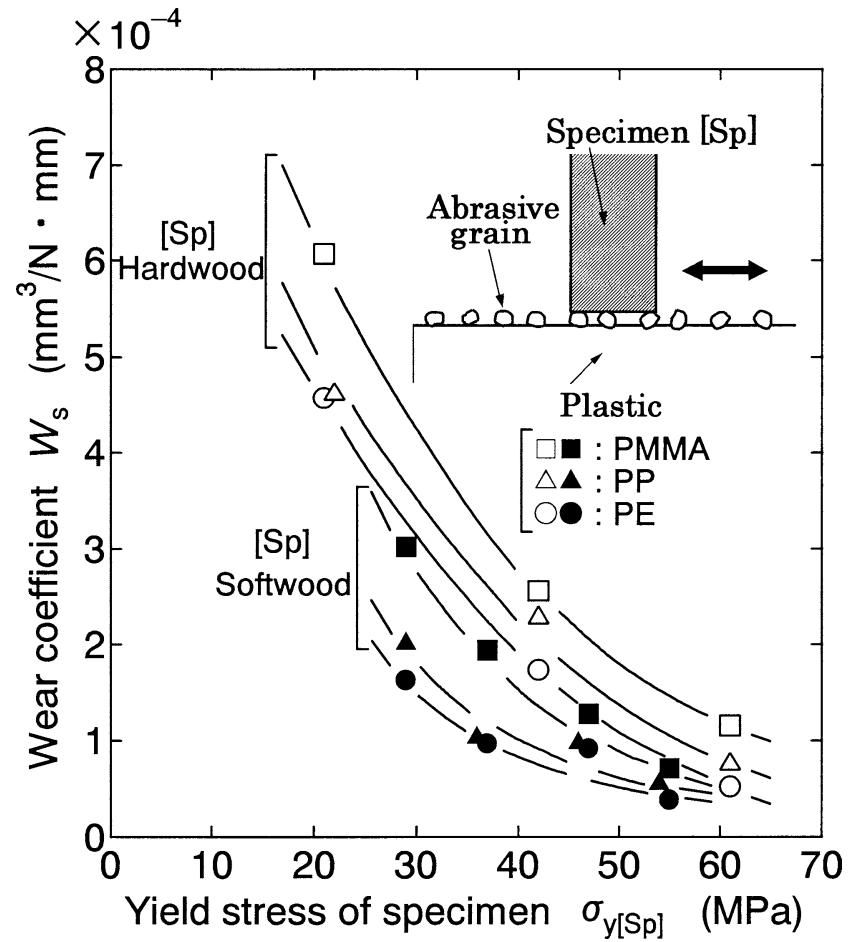

Fig. 4. Relation between the wear coefficients $\left(W_{\mathrm{s}}\right)$ and yield stresses $\left(\sigma_{\mathrm{y}[\mathrm{Sp}]}\right)$ of wood specimens combined with plastic counterface materials

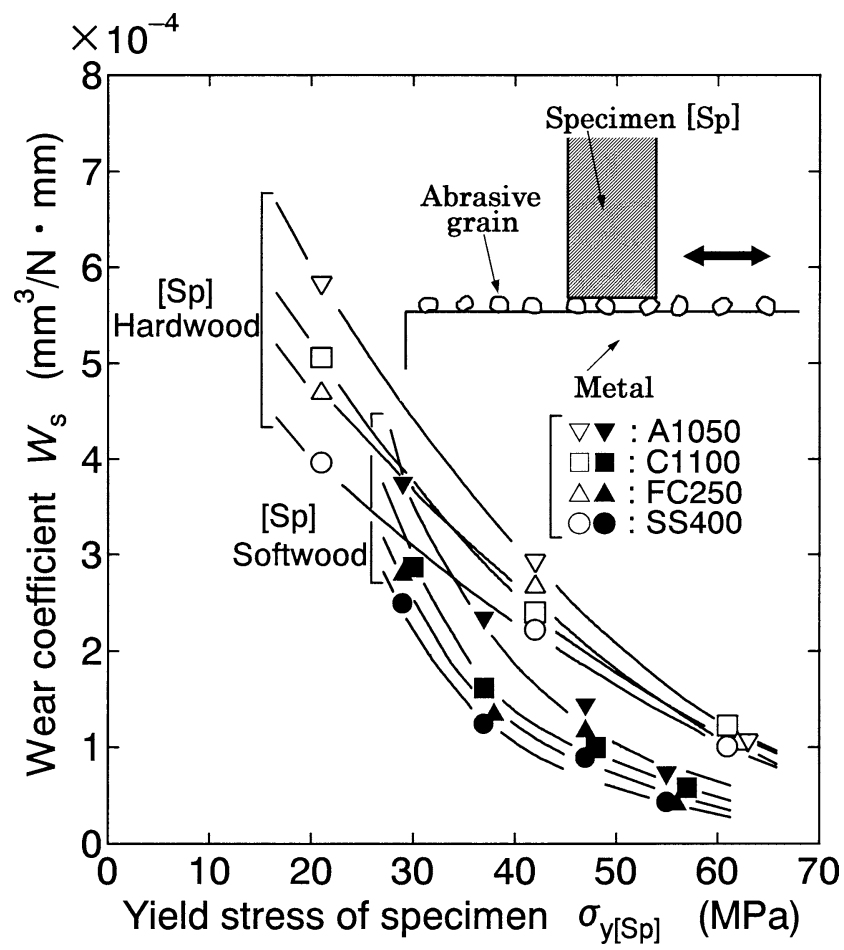

Fig. 5. Relation between the wear coefficients $\left(W_{\mathrm{s}}\right)$ and yield stresses $\left(\sigma_{\mathrm{y}[\mathrm{Sp}]}\right)$ of wood specimens combined with metal counterface materials

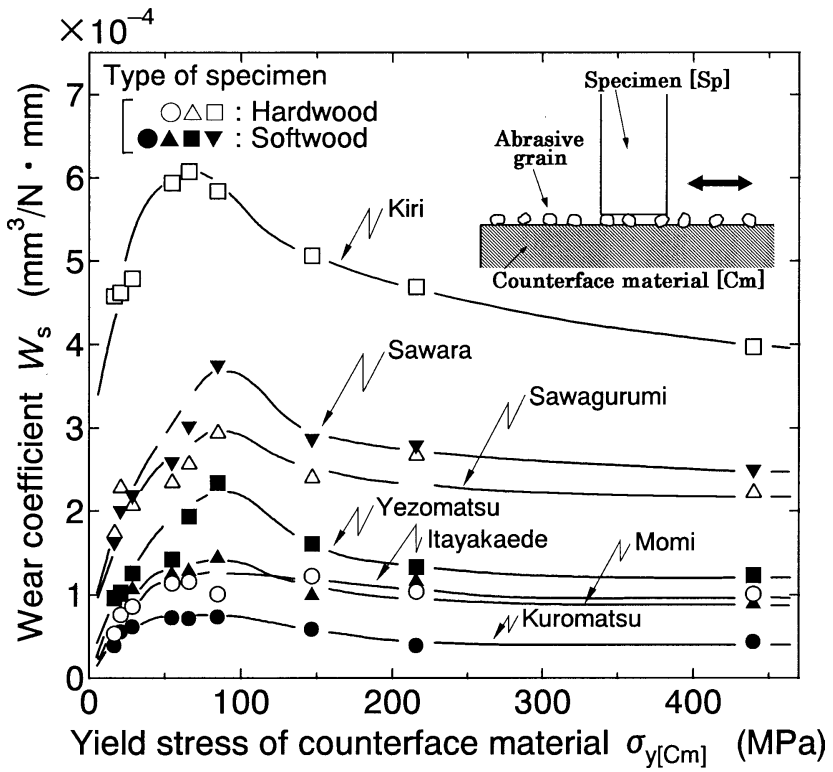

Fig. 6. Relation between the wear coefficients $\left(W_{\mathrm{s}}\right)$ of wood specimens and yield stresses $\left(\sigma_{\mathrm{y}[\mathrm{Cm}]}\right)$ of counterface materials
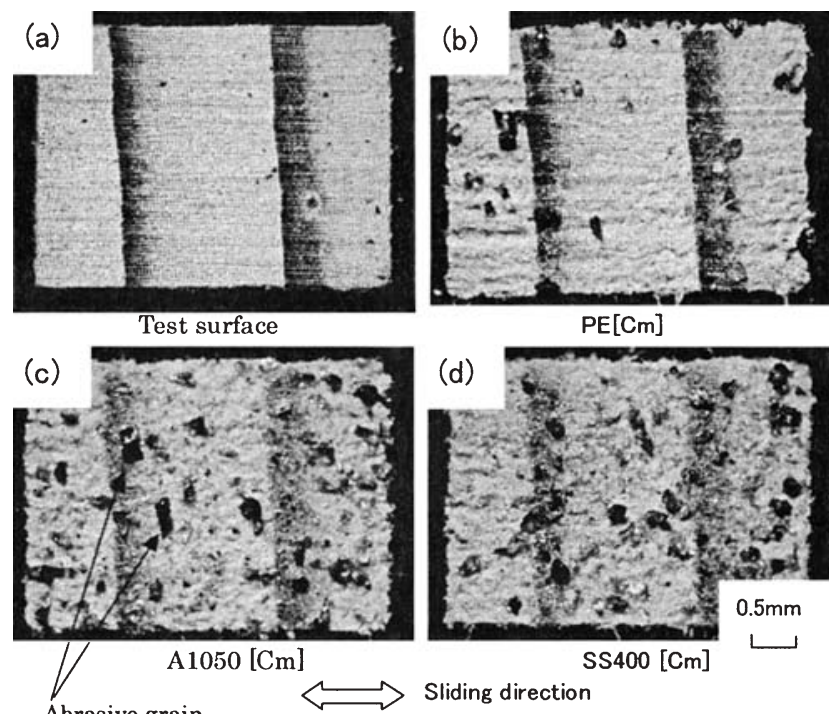

Fig. 7. Friction surface of yezomatsu used for wood specimens. a specimen surface before the wear test. b-d Wood specimen surface combined with polyethylene (PE), A1050, and SS400 counterface materials, respectively

deviation $\left(R_{\mathrm{a}}\right)$ of the surface profile was calculated from five measurements using a roughness tester traced over the surface in the friction direction. The mean surface roughness of these specimens was $1.48,3.71,8.44$, and $5.98 \mu \mathrm{m}$ for the surfaces in Fig. 7a-d, respectively; and it was 2.21, 3.84, 5.80, and $4.97 \mu \mathrm{m}$, respectively, for those in Fig. 8a-d. These results show that the abrasive grains adhere most readily to the surface of the yezomatsu and sawagurumi specimens when rubbed against A1050 counterface material, which also has the highest $R_{\mathrm{a}}$ value. Consequently, it is thought that the peak $W_{\mathrm{s}}$ in Fig. 6 is largest because of the 


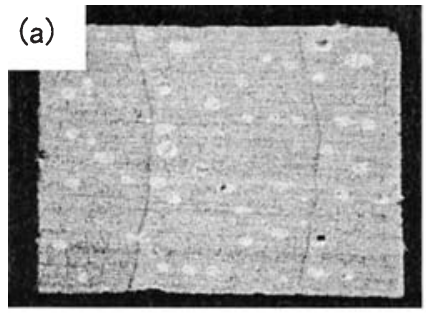

(b)

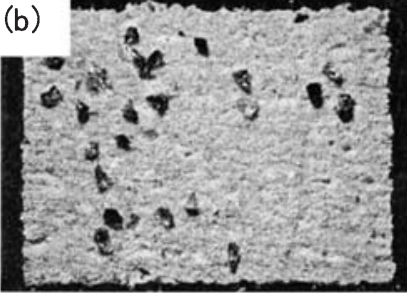

Test surface
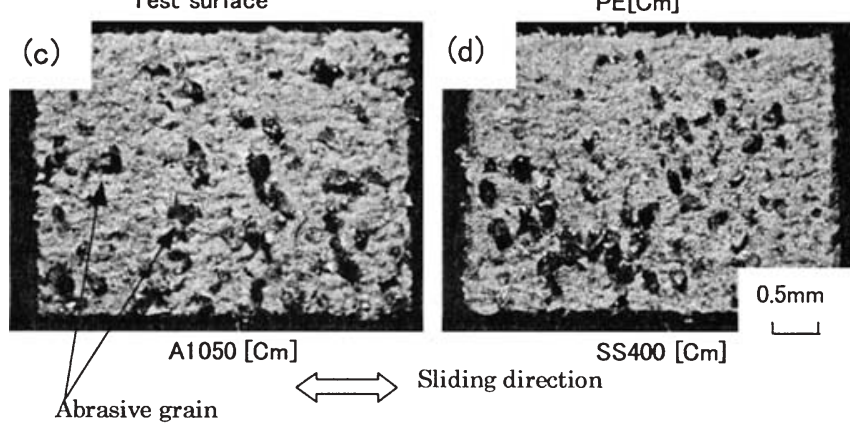

Fig. 8. Friction surface of sawagurumi used for wood specimens. a-d Refer to Fig. 7

increase in the number of abrasive grains scratching the wood specimen.

\section{Conclusions}

The abrasion characteristics of combinations of various woods and counterface materials during three-body abra- sive wear were examined. It was found that the wear coefficient of wood specimens was smallest for combinations in which the wood specimen had a high yield stress. The wear coefficient increased with increasing yield stress of the counterface material up to a maximum value, decreasing gradually thereafter. This result indicated that a peak value existed for the wear coefficient in combination with the counterface material. At the peak abrasion, the loose abrasive grains adhered most readily to the surface of the wood specimen, yielding a rougher surface profile.

Acknowledgment We thank S. Moriyama for extensive assistance with the experimental apparatus.

\section{References}

1. Burwell J (1957) Survey of possible wear mechanisms. Wear 1:119_ 141

2. Rabinowicz E, Mutis A (1965) Effect of abrasive particle size on wear. Wear 8:381-390

3. Ohtani T, Yakou T, Kitayama S (1996) Conditions and origin of the critical grain size effect on the abrasive wear of woods (in Japanese). Mokuzai Gakkaishi 42:1057-1063

4. Suzuki M (1977) The standardized test of the abrasion of wood and its anisotropy (in Japanese). Bull Gov For Exp Station 298:111-141

5. Ohtani T, Yakou T, Kitayama S (2001) Two-body and three-body abrasive wear properties of katsura wood. J Wood Sci 47:87-93

6. Ura A, Hirano F (1977) On the effect of the combination of mating materials on the abrasive wear (in Japanese). Lubrication 22:335340

7. Yakou T, Ohtani T, Kitayama S (1996) Comparison of unidirectional and reciprocating abrasive wear properties in aluminum and katsura wood (in Japanese). Mokuzai Gakkaishi 42:457-463 